\title{
Growth of Vertically Aligned Carbon Nanotubes by RF-DC Plasma Chemical Vapor Deposition
}

\author{
Yasuaki Hayashi, Hideto Sawada and Hideyuki Takagi \\ Kyoto Institute of Technology \\ Japan
}

\section{Introduction}

Large-area, vertically aligned CNTs have a variety of applications like field electron emitters for cathode ray lighting tubes (Saito et al., 1998), field emission displays (FED) (Sohn et al., 2001; Wang et al., 2001), backlight flat lamps in liquid-crystal displays (Bonard et al., 2001; Yoo et al., 2007), X-ray sources (Yue et al., 2002; Haga et al., 2004), as well as large surfacearea electrodes for super-capacitors (Frackowiak et al., 2000; Futaba et al., 2006; McDonough et al., 2009), because of their higher aspect ratio and longer lifetime. A high electric field in the sheath generated in plasma enables self-standing and vertically aligned growth of carbon nanotubes (CNT) on substrates during plasma enhanced-chemical vapor deposition (PE-CVD). Power sources of direct-current (DC) with and without hot-filaments (Ren et al., 1998; Huang et al., 1998; Hayashi et al., 2001; Chhowalla et al., 2001), microwave (Sung et al., 1999; Murakami et al., 2000; Hayashi et al., 2002; Kojima et al., 2005), and radio-frequency (RF) (Hirao et al., 2001; Delzeit et al., 2002; Honda et al., 2003; Sato et al., 2006) have been utilized for generating plasma in vertically aligned growth of CNT by PE-CVD. DC plasma can generate the sheath of high electric field on the cathode. High electric filed sheath can also be generated on RF electrode by self-bias, but only under lower gas pressure (Hirao et al., 2001; Kaneko et al., 2005). Both DC and RF plasmas have the potential for large-area growth of CNT. Higher density plasma can be generated by DC or microwave power sources.

Vertically aligned CNTs are grown owing to a pull-up force exerted by the high electric field in the sheath formed on a substrate.Increasing the gas pressure makes the sheath thinner to form a higher electric field on the substrate without increasing ion bombardment energy (Hayashi et al., 2010). Therefore, DC plasma has the potential to grow vertically aligend CNTs on a large-area substrate under high gas pressure. The problem of applying DC plasma for the growth of CNTs is the instability of DC glow discharge by occasionally generated arcing. Hence, a new plasma CVD method called RF-DC plasma CVD was developed (Hayashi et al., 2006; Hayashi et al., 2010). This method applies DC plasma under assistance of RF plasma for discharge stabilization. It was demonstrated that, with an increase in the RF power, the firing potential of DC discharge decreases and the DC discharge current for the same discharge voltage increases. These features of RF-DC plasma mean that the impedance of DC discharge decreases under RF plasma generation. Arcing occurs occasionally at the cusped points on the electrodes, where high electric fields exist. 
Stable glow discharge can continue with less frequent arcing under the condition of low impedance. Thus, with the generation of RF plasma, the DC glow discharge is more stable. The perpendicular alignment of CNTs grown by PE-CVD on a substrate surface is more than that of CNTs oriented electrically after dispersion on the substrate. However, the density of aligned CNTs grown by PE-CVD as well as thermal CVD is too high to decrease the electric field at their tips. The density by PE-CVD is of the order of $10^{9} / \mathrm{cm}^{2}$, which corresponds to an average spacing between CNTs of a few hundred nm. In comparison, the density of CNTs formed by thermal CVD is of the order of $1010 / \mathrm{cm}^{2}$. The enhancement factor of electric field at the tip of CNT decreases with the increase in spacing between them because of the field-screening effect. It was calculated that the maximum density of field electron emission is obtained when the spacing between CNTs is comparable to their height (Nilsson, 2000; Suh, 2002; Jo, 2003). The spacing for CNTs grown by PE-CVD is generally much larger than the height. Therefore, to increase the density of field electron emission from aligned CNTs, the density of CNTs should be reduced by controlling the growth or by the method of post-treatment. For example, the growth of pattered arrays was controlled using electron beam lithography of catalyst (Teo, 2002), or by post-treatment carried out by a process with energetic plasma ions (Weng, 2004).

This chapter first shows the features of RF-DC PE-CVD plasma obtained through the diagnostics by the method of Langmuir probe, and the result of CNT growth analysis. Second, it shows the increase in density of field electron emission by the dip-dry method of post treatment, which is simple and suitable for vertically aligned CNTs grown over large-area.

\section{Vertically aligned CNT growth by RF-DC PE-CVD}

\subsection{Experimental system of RF-DC PE-CVD}

Figure 1 shows the schematic of the RF-DC plasma CVD system. Three electrodes (i. e., a 13.56 $\mathrm{MHz}$ RF electrode, a grounded electrode, and a DC cathode) are vertically fixed parallel to each other in a vacuum chamber. The distance between the RF and the grounded electrode is $10 \mathrm{~mm}$, and that between the DC cathode and grounded electrode is $15 \mathrm{~mm}$. The DC cathode, which is round in shape with $110 \mathrm{~mm}$ in diameter, having a hole at the center, also plays the role of a substrate holder. A substrate up to $75 \times 75 \mathrm{~mm}^{2}$ can be mounted on the cathode. An RF plasma is generated between the RF electrode and the grounded electrode, while a DC plasma is generated between the DC cathode and the grounded electrode. The grounded electrode is ring-shaped to facilitate passage of a part of the RF generated plasma into the space of DC discharge. The inside of the ring is covered with a mesh or wires, or is left without them. RF power induces not more than $500 \mathrm{~W}$ to the RF electrode. a negative bias not more than $650 \mathrm{~V}$ is applied to the cathode electrode. Substrate temperature is measured with a pyrometer at the backside of the substrate or on the surface of the substrate through the center hole of the RF electrode.

\subsection{Features of RF-DC plasma}

Figure 2 shows the relationship between the voltage and the current of DC discharge with and without RF plasmas in pure hydrogen, measured in the RF-DC plasma CVD system. The current shows average values measured with increasing and decreasing voltage. The firing potential without RF plasma was approximately $300 \mathrm{~V}$, which decreased to a voltage of around $100 \mathrm{~V}$ with RF plasma. The discharge voltage decreased from $350 \mathrm{~V}$ to $270 \mathrm{~V}$ 


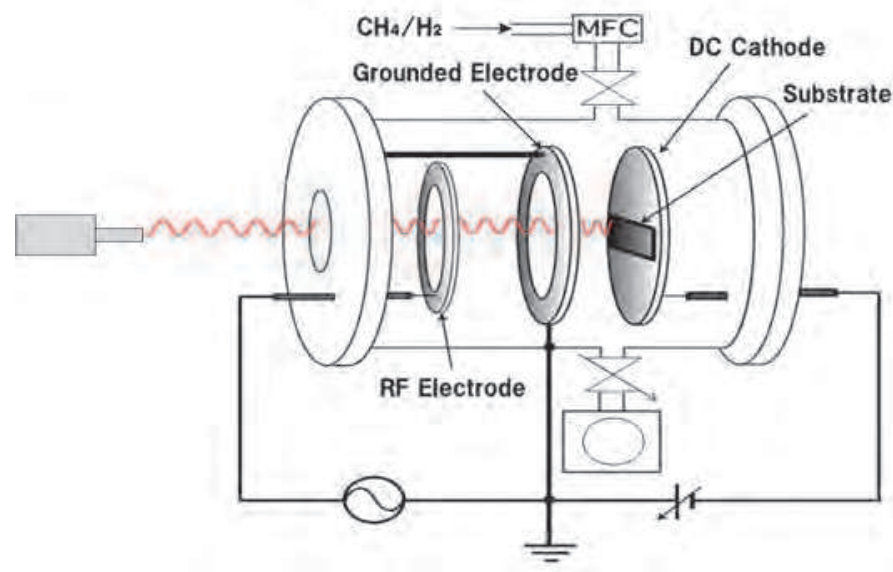

Fig. 1. Schematic of the RF-DC plasma CVD system. RF plasma and DC plasma are generated between RF electrode and grounded electrode and between DC cathode and grounded electrode, respectively.

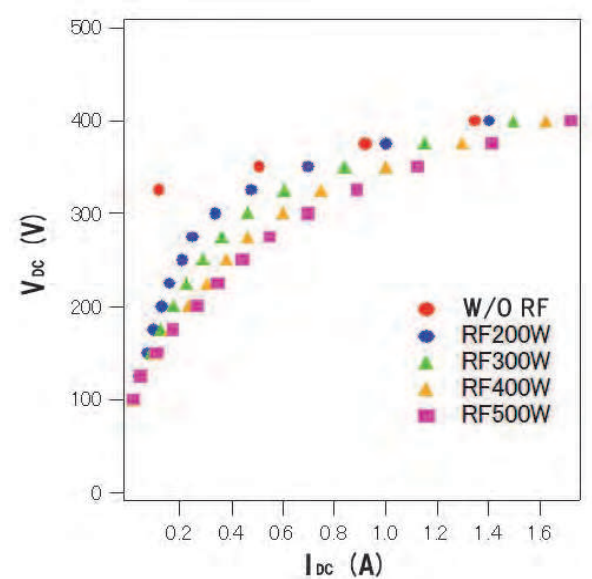

Fig. 2. Relationship between voltage and current of DC discharge with and without RF plasma in pure hydrogen.

at $0.5 \mathrm{~A}$ current, and from $380 \mathrm{~V}$ to $340 \mathrm{~V}$ at $1.0 \mathrm{~A}$ current by the generation of RF plasma with a power of $500 \mathrm{~W}$. The impedance of DC discharge decreased with the increase of RF power.

In DC plasma, arcing occasionally occurs at cusped points on the surface of an electrode because high electric fields are formed there. During the fluctuation of plasma state, the electric field at a cusped point accidentally exceeds the value of arcing induction. In order to prevent arcing, DC voltage should be lowered to within the limit of discharge continuation. Thus, stable DC discharge with less arcing is expected under the condition of low impedance. 


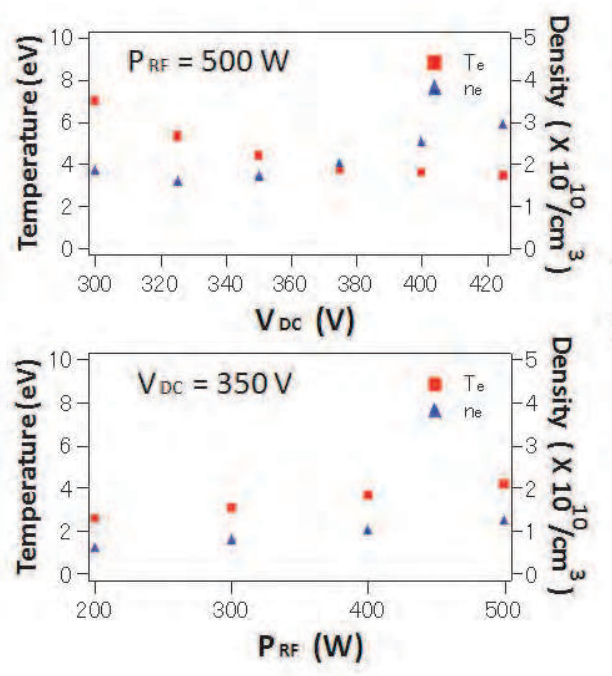

(a)

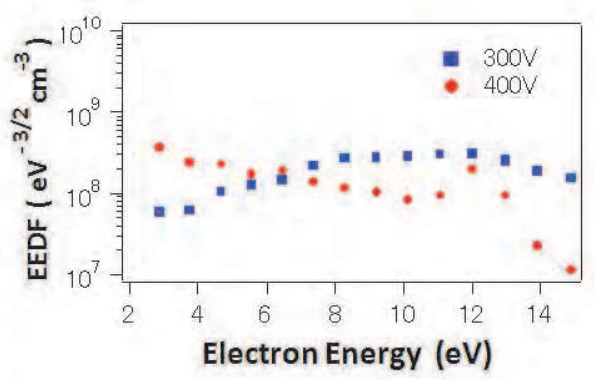

(b)

Fig. 3. Features of RF-DC plasma. (a) DC voltage and RF power dependence of electron temperature $(\mathrm{Te})$ and electron density (ne). (b) Electron energy distribution function (EEDF) for DC voltage of $300 \mathrm{~V}$ and $400 \mathrm{~V}$ with RF power of $500 \mathrm{~W}$.

The plasma diagnostics of RF-DC plasma was carried out by the method of Langmuir probe. The tip of Langmuir probe was a tungsten wire of $0.3 \mathrm{~mm}$ in diameter and $10 \mathrm{~mm}$ in length. The probe was set parallel to the cathode surface at a distance of $10 \mathrm{~mm}$ and its longitudinal center at $10 \mathrm{~mm}$ from the center axis of electrodes. The diagnostic result is shown in Fig.3. Figure 3(a) shows the dependence of electron temperature and density on DC voltage under a constant RF power of $500 \mathrm{~W}$ (upper), as well as their dependence on RF power under a constant DC voltage of $350 \mathrm{~V}$ (lower). The electron temperature decreases with increase of DC voltage or with decrease of RF power. In other words, higher electron temperature is obtained under a larger influence of RF plasma. Electron density gradually increases with increase in DC voltage and RF power. Typical electron energy distribution function (EEDF) for DC voltage of 300 and $400 \mathrm{~V}$ with RF power of $500 \mathrm{~W}$ is shown in Fig.3(b). Comparatively higher energy electrons exist under the condition of higher RF power, i. e., they increase with the increase in ratio of RF power to DC discharge voltage. Because the binding energy of $\mathrm{H}-\mathrm{H}$ and $\mathrm{C}-\mathrm{H}$ is $4.5 \mathrm{eV}$ and $4.3 \mathrm{eV}$, respectively, electrons of energy higher than these values promote the dissociation of hydrogen and hydrocarbon molecules in a plasma. Active species for the growth of CNTs are produced by such energetic electrons.

\subsection{Growth of vertically aligned CNTs}

Iron foil substrates of $0.2 \mathrm{~mm}$ thickness, which had been ultrasonically cleaned in ethanol, were fixed onto the cathode electrode. They were pretreated before CNT growth in a pure hydrogen plasma under a DC voltage of $350 \mathrm{~V}$ with RF power of $500 \mathrm{~W}$ and pressure of 2200 Pa for $15 \mathrm{~min}$. Methane gas was added to hydrogen by $20 \%$ under the same operating 
pressure during the growth of CNTs for $15 \mathrm{~min}$. The DC voltage was increased from $470 \mathrm{~V}$ to $620 \mathrm{~V}$ to maintain the substrate temperature at $700{ }^{\circ} \mathrm{C}$ throughout the pretreatment and growth process. For comparing the effect of RF plasma, CNT growth was also carried out with a lower RF power of $300 \mathrm{~W}$ at the same substrate temperature.

\subsubsection{Vertically aligned CNTs}

Figure 4 shows scanning electron microscopy (SEM) images of vertically aligned CNTs, grown with an RF power of $500 \mathrm{~W}$. Multi-walled CNTs of several tens of $\mathrm{nm}$ in diameter and several microns in length are observed. The density of the CNTs is of the order of $10^{9} / \mathrm{cm}^{2}$. All of the CNTs have catalyst iron particles at their tips. Individual CNT grew selfstanding without sticking to each other by the van der Waals attraction. Such vertically aligned CNTs were observed to grow all over the surface of the iron foil substrate of $75 \mathrm{~mm}$ $\times 75 \mathrm{~mm}$ dimension (Hayashi et al., 2010). CNTs grown with RF power of $300 \mathrm{~W}$ showed similar alignment in growth as shown in Fig.4. The length of CNTs was found to be about 6 $\mu \mathrm{m}$. Raman analysis of the CNTs showed the peak height ratio of Graphite to Defect (G/D) vary between 1.1 and 1.3 .
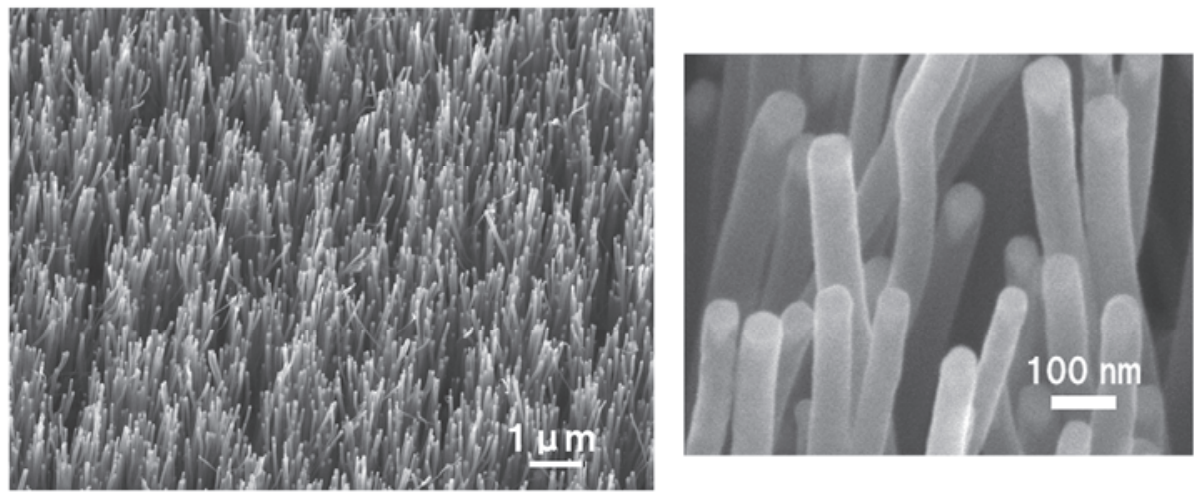

Fig. 4. SEM images of vertically aligned CNTs.

\subsubsection{Early stages of growth of vertically aligned CNTs}

To analyze the early stages of vertically aligned growth of CNTs, the substrate surface was observed by SEM. The SEM images of substrate surface after 1 min growth of CNTs under the condition of RF power of $300 \mathrm{~W}$ (a) and $500 \mathrm{~W}$ (b) are shown in Fig.5. They show isolated or strung particles of more or less $100 \mathrm{~nm}$ and smaller particles of a few to several tens of $\mathrm{nm}$ in sizes. The smaller particles are observed more remarkably for the $500 \mathrm{~W}$ RF power (Fig.5(b)). Some short fibers of few tens of $\mathrm{nm}$ in diameter, which should be the sprouts of CNTs, are observed in magnified oblique views. The fibers grown with $500 \mathrm{~W} R \mathrm{R}$ power are longer than those with $300 \mathrm{~W}$ RF power. The result means that the initial growth of CNT with $500 \mathrm{~W}$ RF power is faster than that with $300 \mathrm{~W}$ RF power. As was discussed in section 2.2, because electron temperature increases with the increase of RF power, more active species for the growth of CNTs are produced under the condition of $500 \mathrm{~W}$ RF power. However, the diameter of the short fibers is smaller than that of the vertically grown CNTs in Fig.4. The growth of CNT can be explained by the vapor-liquid-solid (VLS) growth model (Tibbetts, 

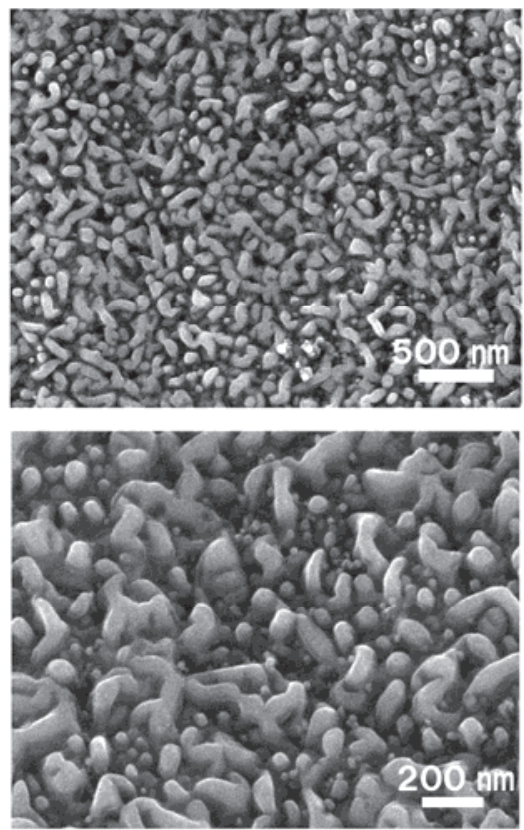

(a)
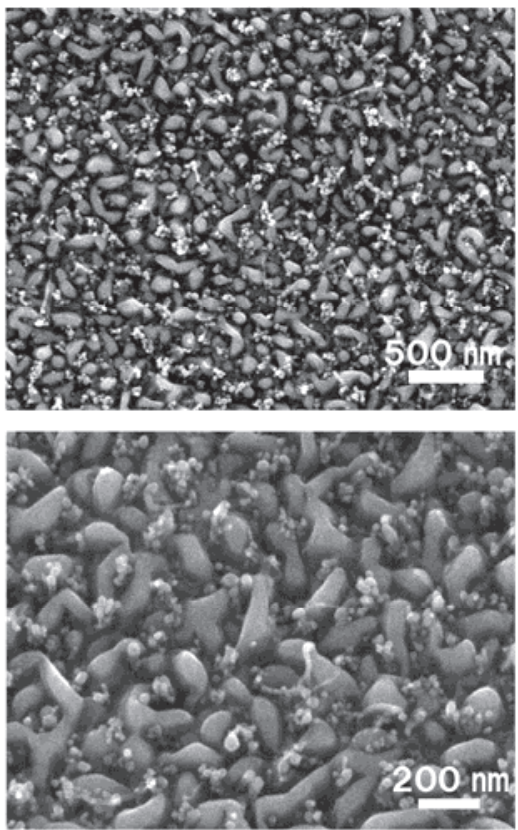

(b)

Fig. 5. SEM images of substrate surface after 1 min growth with RF power of (a) $300 \mathrm{~W}$ and (b) $500 \mathrm{~W}$. Upper and lower images are top and magnified oblique views, respectively.

1984; Kanzow \& Ding, 1999; Hayashi et al., 2005), which advocates that thinner CNTs grow faster because smaller catalyst ion particles absorb and extract carbon faster. Therefore, the thicker CNTs that are observed in Fig.4 should grow later and survive ion bombardment.

\section{Field emission properties and post treatment of vertically aligned CNTs}

\subsection{Field emission properties of vertically aligned CNTs}

Field emission properties of vertically aligned CNTs grown by RF-DC PE-CVD were investigated under the application of high voltage in the base pressure of $4 \times 10^{-5} \mathrm{~Pa}$. Negative bias voltage was applied to the CNTs on an iron substrate with a grounded counter electrode. The two electrodes were spaced at $240 \mu \mathrm{m}$ apart. Figure 6 shows the dependence of the field emission current per unit area (which is defined as if electrons emit uniformly over $0.3 \mathrm{~cm}$ in diameter) on the applied voltage (a) and its Fowler-Nordheim plot (b) for CNTs grown by RF-DC PE-CVD at RF power of $500 \mathrm{~W}$. The slope 'b' of linear relation of Fowler-Nordheim plot in higher applied voltage (lower $1 / \mathrm{V})$ is expressed as

$$
\mathrm{b}=-6.83 \times 10^{7} \mathrm{~d} \phi^{3 / 2} / \beta(\mathrm{V})
$$

,where $\mathrm{d}, \phi$ and $\beta$ are electrode spacing (in $\mathrm{cm}$ ), the work function (in $\mathrm{eV}$ ) and fieldenhancement factor, respectively (Ishikawa et al., 1993; Forbes, 1999). When $\mathrm{d}=240 \mu \mathrm{m}$ and $\phi=4.7 \mathrm{eV}$ (Gao et al., 2001) $\beta=1.7 \times 10^{3}$ is obtained for the slope in Fig.6(b), by eq. (1). 


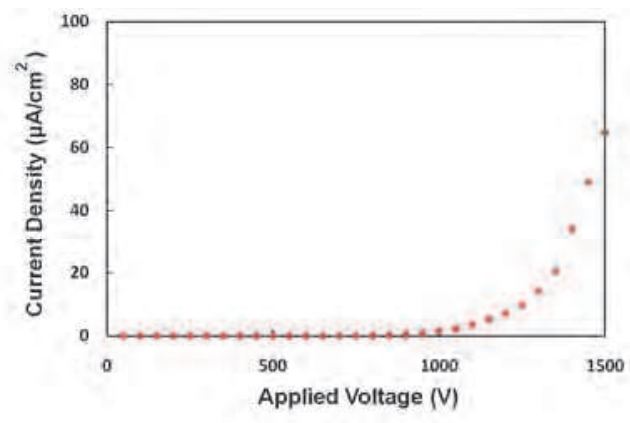

(a)

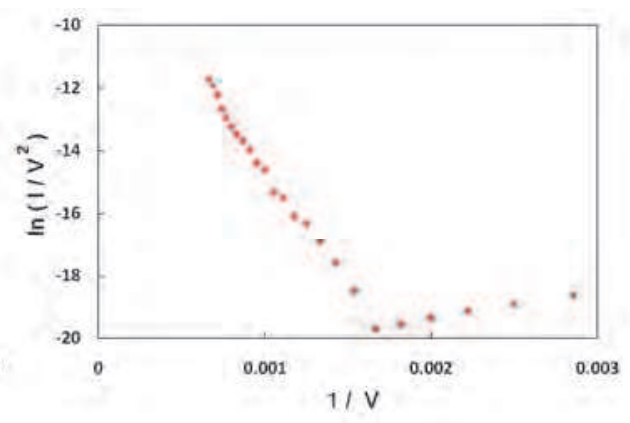

(b)

Fig. 6. Relationship between field emission current and applied voltage for CNTs grown by RF-DC PE-CVD with RF power of 500 W. (a) Dependence of current density on applied voltage. (b) Fowler-Nordheim plot of The data shown in (a).

\subsection{Effect of post treatment of vertically aligned CNTs}

The density of vertically aligned CNTs grown by CVD is so high that the field-screening effect (Nilsson et al., 2000; Suh et al., 2002; Jo et al., 2003) decreases electron emission current as a result of decrease of field-enhancement factor. In order to increase emission current by restricting the field-screening effect, the dip-dry post-treatment method was carried out to assemble vertically aligned CNTs into conics. Such a post-treatment had been done by embedding CNTs into a silicon dioxide, followed by HF etching, water rinsing, and nitrogen drying (Busta et al., 2004). However, in this case, approximately only ten CNTs were bundled together, which is not enough for the purpose. Therefore, we developed a simpler and effective post-treatment process, in which CNTs were first dipped in ethanol or distilled water, and air dried. The SEM images of CNTs post-treated by above method are shown in Fig.7 and Fig.8.
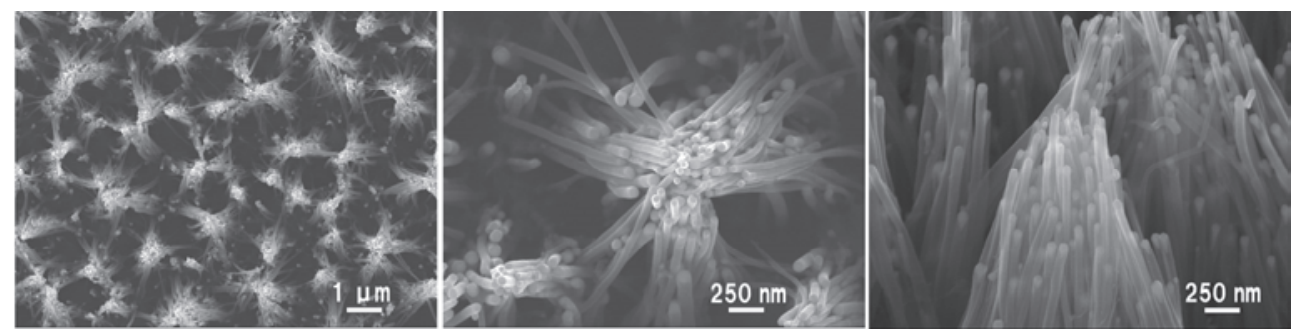

Fig. 7. SEM images of post treated vertically aligned CNTs. The left two are top views and the right is an oblique view.

Figure 7 shows that CNTs are bundled at the tips while their bottoms are left at stuck positions on the substrate. They form conics and decrease the number of electron emission sites. The mechanism of CNT bundling can be explained by the fact that capillary and surface tension forces of solutions act on CNTs at their flexible tips during drying (Busta et al., 2004; Futaba et al., 2006; Hayamizu et al., 2008) and that the tips of CNTs gather to each other by the van der Waals interactions after they are completely dried. 


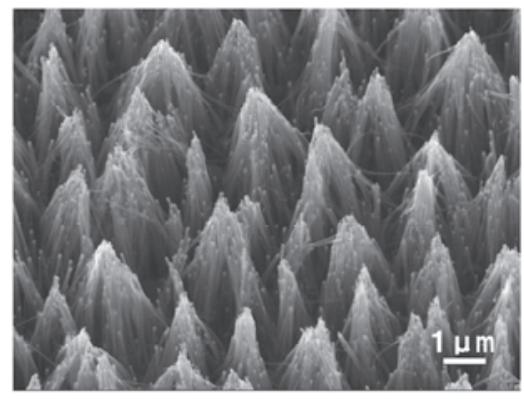

(a)

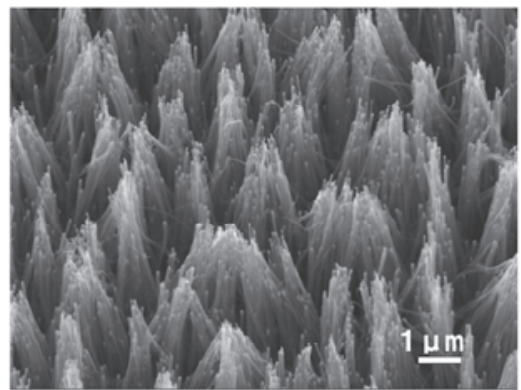

(b)

Fig. 8. SEM images of post treated vertically aligned CNTs; (a) dipped and dried in ethanol, (b) dipped and dried in distilled water.

The density of as-grown CNTs shown in Fig.4 was $4.4 \times 10^{9} \mathrm{~cm}^{-2}$. The number of CNT bundles after post-treatment in ethanol and distilled water was $3.9 \times 10^{7} \mathrm{~cm}^{-2}$ and $2.2 \times 10^{7} \mathrm{~cm}^{-2}$, respectively. The result means that around $100 \mathrm{CNTs}$ were bundled by the post-treatment in ethanol and more than 100 CNTs in distilled water. The tips of bundled CNTs post-treated in ethanol are more tightly stuck together compared to those post-treated in distilled water (Fig.8). The surface tension of ethanol at $20^{\circ} \mathrm{C}$ is $22.40 \mathrm{mN} / \mathrm{m}$, while that of distilled water at $20^{\circ} \mathrm{C}$ is $72.75 \mathrm{mN} / \mathrm{m}$. Since higher surface tension gathers larger number of CNTs against restoring force from the bottom during drying, more CNTs are bundled in distilled water than in ethanol. After complete drying, the restoring force spreads out bundled CNTs competing with the van der Waals attractive force, especially for bundles formed by larger number of CNTs.

The field emission properties of post-treated CNTs and as-grown ones were compared. Small chips, which were cut from a sheet of $50 \mathrm{~mm} \times 50 \mathrm{~mm}$ vertically aligned CNTs on an iron foil grown by RF-DC PE-CVD, were used for the measurement. The relationship measured between field emission current and applied voltage are shown in Fig.9. Highest current density is obtained for CNTs post-treated in ethanol. It is followed by CNTs post-treated in distilled water, and then by the as-grown CNTs. The field-enhancement factors for posttreated CNTs in ethanol, distilled water, and as-grown ones, evaluated from the slope in the Fowler-Nordheim plot were $2.9 \times 10^{3}, 2.0 \times 10^{3}$, and $1.8 \times 10^{3}$, respectively. The result indicates that the evaluated field-enhancement factors reflect the field-screening effect.

\section{Summary}

Large-area, vertically aligned CNTs were grown by DC plasma-enhanced CVD under RF plasma assistance. The firing potential and discharge current in a DC plasma was found to decrease with an increased power of RF plasma. In the plasma, stable glow discharge continued with less arcing. Higher energy electrons increased with the increasing ratio of RF power to DC discharge voltage. They promoted radical production in plasma, leading to increase in CNT growth rate.

Field emission properties of as-grown and post-treated vertically aligned CNTs, grown by RF-DC PE-CVD, were investigated. Dip-dry post-treatment in ethanol was effective for 


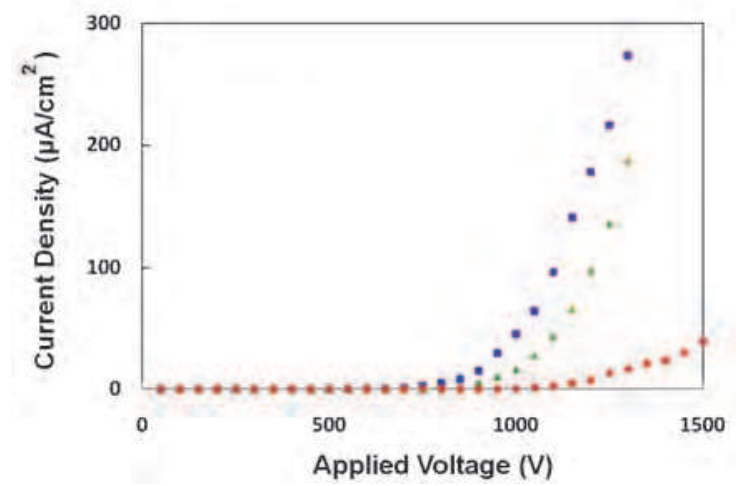

Fig. 9. Relationship between field emission current and applied voltage for as-grown CNTs (red circles) and post-treated CNTs in distilled water (green triangles) and in ethanol (blue rectangles).

reducing the density of field-emission sites, leading to a restriction of the field-screening effect, increasing the field-enhancement factor and consequently improving the field emission property of vertically aligned CNTs.

\section{Acknowledgment}

The authors thank Mr. Takashi Nakamura and Mr. Kazunori Odani for experimental assistance, and thank Ms. Risa Utsunomiya in Nissin Electric Co. Ltd. for partly supporting the present work.

\section{References}

Bonard, J. ; Stoeckli, T. ; Noury, O. \& Chatelain A. (2001). Field emission from cylindrical carbo nanotube cathodes: Possibilities for lumininescent tubes, Applied Physics Letters, 78, 2775-2777.

Busta, H ; Tolt, Z. ; Montgomery, J. \& Feinerman, A. (2004). Field Emission from Teepeeshaped Carbon Nanotube Bundles, Technical Digest of the 17th International Vacuum Nanoelectronics Conference : IVNC 2004, 30-31.

Chhowalla, M. ; Teo, K. B. K. ; Ducati, C. ; Rupesinghe, N. L. ; Amaratunga, G. A. J. ; Ferrari, A. C. ; Roy, D. ; Robertson, J. \& Milne, W. I. (2001). Growth process conditions of vertically aligned carbon nanotubes using plasma enhanced chemical vapor deposition, Journal of Applied Physics, 90, 5308-5317.

Delzeit, L. D. ; McAninch, I. ; Crude, B. A. ; Hash, D. ; Chen, B. ; Han, J. \& Meyyappan, M. (2002). Journal of Applied Physics, 91, 6027-6033.

Forbes, R. G. (1999), Field emission : New theory for the derivation of emission area from a Fowler-Nordheim plot, Journal of Vacuum Science and Technology B, 17, 526-533.

Frackowiak, E. ; Metenier, K. ; Bertagna, V. \& Beguin, F. (2000). Supercapacitor electrodes from multiwalled carbon nanotubes, Applied Physics Letters, 77, 2421-2423.

Futaba, D. N. ; Hata, K. ; Yamada, T. ; Hiraoka, T. ; Hayamizu, Y.; Kakudate, Y. ; Tanaike, O. ; Hatori, H. ; Yumura, M. \& Iijima, S. (2006). Shape-engineerable and highly densely 
packes single-walled carbon nanotubes and their application as super-capacito electrodes, Nature Materials, 5, 987-994.

Gao, R. ; Pan, Z.\& Wang, Z. L. (2001). Work function at the tips of multiwalled carbon nanotubes, Applied Physics Letters, 78, 1757-1759.

Haga, A. ; Senda, S. ; Sakai, Y. ; Mizuta, Y. ; Kita, S. \& Okuyama, F. (2004). Aminiature x-ray tube, Applied Physics Letters, 84, 2208-2210.

Hayamizu, Y. ; Yamada, T. ; Mizuno, K. ; Davis, R. C. ; Futaba, D. N. ; Yumura, M. \& Hata, K. (2008). Integrated three-dimensional microelectromechanical devices from processable carbon nanotube wafers, Nature Nanotechnology, 3, 289-294.

Hayashi, H. ; Koga, M. ; Kashirajima, J. ; Takahashi, K. ; Hayashi, Y. \& Nishino, S. (2002). Large-Scale Synthesis of Aligned Carbon Nanotubes by Surface-Wave-Excited Microwave-Plasma-Enhanced Chemical Vapor Deposition, Japanese Journal of Applied Physics, 41, L1488-L1491.

Hayashi, Y. ; Negishi, T. \& Nishino, S. (2001). Growth of well-aligend carbon nantubes on nickel by ho-filament-assisted dc plasma chemical vapor deposition in a $\mathrm{CH}_{4} / \mathrm{H}_{2}$ plasma, Journal of Vacuum Scinece and Technology A, 19, 1796-1799.

Hayashi, Y.; Watanabe, Y.; Ueda, K. \& Nishino, S. (2005). Analyses of Early Stages of Vertically Aligned Carbon Nantube Grwoth by Plasma-Enhanced Chemical Vapor Deposition, Japanese Journal of Applied Physics, 44, 1549-1553.

Hayashi, Y. ; Fukumura, T. ; Isshiki, T. \& Utsunomiya, R. (2006). Highly Alogned Growth of Carbon Nanotubes by RF-Plasma-Assisted DC Plasam Chemical Vapor Deposition at High Pressure, Japanese Journal of Applied Physics, 45, 8308-8310.

Hayashi, Y.; Fukumura, T. ; Odani, K. ; Matsuba, T. \& Utsunomiya, R. (2010). Growth of well-aligned carbon nanotubes by RF-DC plasma chemical vapor deposition, Thin Solid Films, 518, 3506-3508.

Hirao, T. ; Ito, K. ; Furuta, H. ; Yap, Y. K. ; Ikuno, T. ; Honda, S. ; Mori, Y. ; Sasaki, T. \& Oura, K. (2001). Formation of Vertically Aligned Carbon Nantoubes by Dual-RFPlasma Chemical Vapor Deposition, Japanese Journal of Applied Physics, 40, L631L634.

Honda, S. ; Katayama, M. ; Lee, K. ; Ikuno, T. ; Ohkura, S. ; Oura, K. ; Furuta, H. \& Hirao, T. (2003). Low Temperature Synthesis of Aligned Carbon Nanotubes by Inductively Couolpled Plasma Chemical Vapor Deposition Using Pure Methane, Japanese Journal of Applied Physics, 4, L441-L443.

Huang, Z. P. ; Xu, J. W. ; Ren, Z. F. ; Wang, J. H. ; Siegal, M. P. \& Provencio, P. N. (1998). Growth of highly oriented carbon nanotubes by plasma-enhanced hot filmanet chemical vapor deposition, Applied Physics Letters, 73, 3845-3847.

Ishikawa, J. ; Tsuji, H. ; Inoue, K. ; Nagao, M. ; Sasaki, T, ; Kaneko, T. \& Gotoh, Y. (1993). Estimation of Metal-Deposited Field Emitters for the Micro Vacuum Tube, Japanese Journal of Applied Physics, 32, L342-L345.

Jo, S. H. ; Tu, Y. ; Huang, Z. P. ; Carnahan, D. L. ; Wang, D. Z. \& Ren. Z. F. (2003). Effect of lenght and spacing of vertically aligend carbon nanotubes on field emission properties, Applied Physics Letters, 82, 3520-3522.

Kaneko, T.; Matsuoka, H.; Hatakeyama, R. \& Tohji, K. (2005). Effects of Ion Bombardment on Carbon Nanotube Formation in Strongly Magnetized Glow-Discharge Plasmas, Japanese Journal of Applied Physics, 44, 1543-1548. 
Knazow, H \& Ding. A. (1999). Formation mechanism of single-wall carbon nanotubes on liquid-metal partciles, Physical Review B, 60, 11180-11186.

Kojima, Y. ; Kishimoto, S. ; Ohno, Y. ; Sakai, A \& Mizutani, T. (2005). Growth of HighQuality Carbon Nanotubes by Grid-Inserted Plasma-Enhanced Chemical Vapor Deposition for Field Emitters, Japanese Journal of Applied Physics, 44, 2600-2602.

McDonough, J. R. ; Choi, J. W. ; Yang, Y. ; Mantia, F. L. ; Zhang, Y. \& Cui, Y. (2009). Carbon nanofiber supercapacitors with large areal capacitances, Applied Physics Letters, 95, 243109- 1-3.

Murakami, H. ; Hirakawa, M. ; Tanaka, C. \& Yamakawa, H. (2000). Field emission from well-aligned, patterned, carbon nanotube emittes, Applied Physics Letters, 76, 17761778 .

Nilsson, L. ; Groening, O. ; Emmenegger, C. ; Kuettel, O. ; Schaller, E. ; Schlapbach, L. ; Kind, H. ; Bonard, J-M. \& Kem, K. (2000). Scanning field emission from patterned carbon nanotube films, Applied Physics Letters, 76, 2071-2073.

Ren, Z. F. ; Huang, Z. P. ; Xu, J. W. ; Wang, J. H. ; Bush, P. ; Siegal, M. P. \& Provencio, P. N. (1998). Synthesis of Large Arrays of Well-Aligend Carbon Nanotubes on Glass, Science, 282, 1105-1107.

Saito, Y. ; Umemura, S. \& Hamaguchi, K. (1998). Cathode Ray Tube Lighting Elements with Carbon Nanotube Field Emitters, Japanese Journal of Applied Physics, 37, L346L348.

Sato, G. ; Kato, T. ; Oohara, W. \& Hatakeyama, R. (2006). Production and application of reactive plasmas using helicon-wave discharge in very low magnetic fileds, Thin Solid Films, 506-507, 550-554.

Sohn, J. I. ; Lee, S. ; Song, Y. ; Choi, S. ; Cho, K. \& Nam, K. (2001). Patterened selective growth of carbon nanotubes and large field emission from vertically well-aligned carbon nanotube field emission arraays, Applied Physics Letters, 78, 901-903.

Suh, J. S. ; Jeong, K. S. ; Lee, J. S. \& Han, I. (2002). Study of the field-screening effect of highly ordered carbon nanotube arrays, Applied Physics Letters, 80, 2392-2394.

Tsai, S. H. ; Chao, C. W. ; Lee, C. L. \& Shih, H. C. (1999).Bias-enganced nucleation and growth of the aligned carbon nanotubes with open ends under microwave plasma synthesis, Applied Physics Letters, 74, 3462-3464.

Teo, K. B. K. ; Chhowalla, M. ; Amaratunga, G. A. J. ; Milne, W. I. ; Pirio, G. ; Legagneux, P. ; Wyczisk, F. ; Pribat, D. \& Hask, D. G. (2002). Field emission from dense, sparse, and pattaered arrays of carbon nanofibers, Applied Physics Letters, 80, 2011-2013.

Tibbetts, G. G. (1984). WHY ARE CARBON FILAMNETS TUBLRAR?, Journal of Crystal Growth, 66, 632-638.

Wang, Q. H.; Yan, M. \& Chnag, R. P. H. (2001). Flat panel display prototype using gated carbon nanotube field emitters, Applied Physics Letters, 76, 2071-2073.

Weng, C. H. ; Leou, K. C. ; Wei, H. W. ; Juang, Z. Y. ; Wei, M. T. ; Tung, C. H. \& Tsai C. H. (2004). Structural transformation and field emission enhancement of carbon nanofibers by energetic argon plasma post-treatment, Applied Physics Letters, 85, $4732-4734$.

Yoo, H. ; Sung, W. ; Yoon, S. ; Kim, Y. \& Joo, S. (2007). Novel Triode-Type Field Emission and Appropriate Driving Method for Flat Lamp Using Carbon Nanofibers Grwn by Plasma Enhanced Chemical Vapor Deposition, Japanese Journal of Applied Physics, $46,4381-4385$. 
Yue, G. Z. ; Qui, Q. ; Gao, B. ; Cheng, Y. ; Zhang, J. ; Shimoda, H. ; Chang, S. ; Lu, J. P. \& Zhou, O. (2002). Generation of continuous and pulsed diagnostic imaging x-ray radiation using a carbon-nanotube-based filed-emission cathode, Applied Physics Letters, 81, 355-357. 


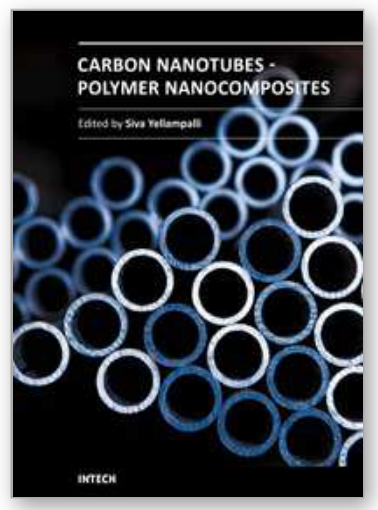

\section{Carbon Nanotubes - Polymer Nanocomposites}

Edited by Dr. Siva Yellampalli

ISBN 978-953-307-498-6

Hard cover, 396 pages

Publisher InTech

Published online 17, August, 2011

Published in print edition August, 2011

Polymer nanocomposites are a class of material with a great deal of promise for potential applications in various industries ranging from construction to aerospace. The main difference between polymeric nanocomposites and conventional composites is the filler that is being used for reinforcement. In the nanocomposites the reinforcement is on the order of nanometer that leads to a very different final macroscopic property. Due to this unique feature polymeric nanocomposites have been studied exclusively in the last decade using various nanofillers such as minerals, sheets or fibers. This books focuses on the preparation and property analysis of polymer nanocomposites with CNTs (fibers) as nano fillers. The book has been divided into three sections. The first section deals with fabrication and property analysis of new carbon nanotube structures. The second section deals with preparation and characterization of polymer composites with CNTs followed by the various applications of polymers with CNTs in the third section.

\section{How to reference}

In order to correctly reference this scholarly work, feel free to copy and paste the following:

Yasuaki Hayashi, Hideto Sawada and Hideyuki Takagi (2011). Growth of Vertically Aligned Carbon Nanotubes by RF-DC Plasma Chemical Vapor Deposition, Carbon Nanotubes - Polymer Nanocomposites, Dr. Siva Yellampalli (Ed.), ISBN: 978-953-307-498-6, InTech, Available from: http://www.intechopen.com/books/carbonnanotubes-polymer-nanocomposites/growth-of-vertically-aligned-carbon-nanotubes-by-rf-dc-plasma-chemicalvapor-deposition

\section{INTECH}

open science | open minds

\section{InTech Europe}

University Campus STeP Ri

Slavka Krautzeka 83/A

51000 Rijeka, Croatia

Phone: +385 (51) 770447

Fax: +385 (51) 686166

www.intechopen.com

\section{InTech China}

Unit 405, Office Block, Hotel Equatorial Shanghai

No.65, Yan An Road (West), Shanghai, 200040, China

中国上海市延安西路65号上海国际贵都大饭店办公楼 405 单元

Phone: +86-21-62489820

Fax: $+86-21-62489821$ 
(C) 2011 The Author(s). Licensee IntechOpen. This chapter is distributed under the terms of the Creative Commons Attribution-NonCommercialShareAlike-3.0 License, which permits use, distribution and reproduction for non-commercial purposes, provided the original is properly cited and derivative works building on this content are distributed under the same license. 